Innovation in Primary Healthcare in the Twenty-first Century

Abstract

COVID-19 once again has shown the world the importance of an urgent need for revitalising the health system based on a strong primary healthcare foundation. It is clear that without a community-based grassroots level care delivery system, Test, Trace and Isolation may not be an effective operational possibility. Politics of health with consequent austerity programme and dependence on secondary hospital care-based system has proved to be ineffective and costly in meeting the changing demands for healthcare of the population-demographic and epidemiological transition with the increasing burden of chronic care; unfinished agenda of Millennium Development Goals (MDGs) and the new challenge of achieving Sustainable Development Gaos (SDGs), including Universal Health Care; improving quality along with access to care; and addressing the existing inequity in healthcare service, politicians and public health leaders must realise and invest in peoplecentred, need-based primary healthcare. Significant and sustained productivity gains can be made through various innovations that can change how quality services are delivered and reduce inequity. In order for primary healthcare to become fit for purpose, it must improve its allocative, technical and service delivery efficiencies; effectiveness and responsiveness of care; access, quality and equity of care; and have an inbuilt monitoring and accountability framework. The system must create a conducive political, social and service delivery environment for innovations. Today, developing countries, as well as developed countries, are all strengthening their primary healthcare system through various innovations to maximise the use of scarce resources to reach all people who need care and minimising cost, wastage and inefficiencies.

Introduction

COVID-19 did not spread to Bangladesh, India or Pakistan and many other countries through their vast porous lands but flew into its airports mostly from Europe and/or America, the Middle East and China. With a health system approach of Test, Trace and Isolation strategy, most of these countries like Taiwan, South Korea, Singapore and Sweden could have contained the community transmission and prevent devastating impacts on human sufferings from the disease and consequent economic hardships without total national lockdown. Pakistan (The Guardian Weekly, 2020), using the vast number of polio-related community health workers and the state of Himachal Pradesh of India (Narin, 2020) using communitybased Accredited Social Health Activists (ASHA) health workers managed remarkably well to contain the virus spreading the disease further and reduced the need for expensive hospital cares. Although, initially, the testing was dependent on sophisticated technology, today, a test can be carried out by grassroots healthcare providers. Recently, Greece's field-based workers, while carrying out testing of stranded refugee population at a Greek Island, have shown that a vast number of testing was possible with the availability of the test results within $30 \mathrm{~min}$. Tracing, Isolation as well as community awareness and building community confidence and support depend on having an efficient and trusted grassroots organisation or system. With new innovations in technology and with widespread mobile phone and digital connectivity, in the twentyfirst century, these tasks have become considerably easier in realising the potential of primary healthcare. COVID-19 has shown the world that the health system in most of the countries in the world, even in rich countries, were not fit to manage the crisis appropriately. The health system in most of the countries today faces significant challenges because of lack of leadership, decade-long austerity programmes and overdependence on secondary hospital-based care. The politicians failed to heed to the growing challenges of the aging population; climate change and its impact on health; 
epidemiological transition from communicable diseases to non-communicable diseases (NCDs); growing new and emerging disease crisis; unfinished agenda of maternal, child, adolescent and reproductive healthcare needs, changing high expectations of population; and rising health expenditure to address more complex healthcare needs. Therefore, with growing fiscal pressure and competing priorities, they find it difficult to allocate adequate and additional resources to the health system let alone for a people-oriented responsive health system. COVID-19 also exposed the wide inequities in access to healthcare services. Unfortunately, in Europe and America, poor and marginalised populations have paid the highest price in relation to the diseases, deaths and economic hardships (Primary Care Development Corporation, 2020; Public Health England, 2020; Rimmer, 2020; Trivedy et al., 2020).Politics of health (Oliver, 2006), and blanching between health and economy, played a major role in the failure to stop the community transmission of COVID-19, causing a huge surge in demand for the treatment of the acutely ill patients. Lack of investment in preventive care, including routine immunisation programmes and managing chronic patients, made it much harder with soaring excess deaths during this period of the COVID-19 crisis. Today, in the twenty-first century, most of the diseases are either determined or caused by behavioural, metabolic or environmental factors (GBD 2015 Risk Factors Collaborators, 2016) and therefore need a preventive and comprehensive care system. As the first point of contact that is expected to address the majority of health needs, strong primary healthcare has the potential to improve health outcomes for people across socio-economic levels and reduce unnecessary use of more expensive specialised services. Primary healthcare can save lives and money while offering a level playing field to achieve more equal access to healthcare. Such positive outcomes will materialise when primary healthcare is a primary source of care that addresses the majority of patients' needs, knows their medical history and helps them to coordinate care with other health services as needed. Evidence shows that better, more accessible primary healthcare results in lower rates of hospitalisations and emergency department use (Huntley et al., 2014; Kirkland et al., 2018; Rosano et al., 2013; van Loenen et al., 2014; Wolters et al., 2017).Primary healthcare can prevent unnecessary procedures and lower the need for the use of costly and scarce facilities, like emergency rooms and hospitals. Robust primary healthcare can delay the onset of chronic diseases and reduce mortality rates. Its role in prevention, from encouraging people to adopt a healthy lifestyle, such as wearing a mask, maintaining social distancing, stopping smoking, using a seat belt to early detection of hypertension, diabetes, breast and colon cancer, is critical to people's lives. Quality primary healthcare is linked to higher patient satisfaction and seeking care early. The increased recognition of the primacy of strong primary healthcare is not new. Today more than ever it is realised a strengthened primary healthcare systems have the potential to improve health outcomes across socioeconomic levels, to make health systems more people-centred, and to improve health system efficiency in the twentyfirst century (Macinko et al., 2009) and overall come out of devastating consequences of COVID-19health outcomes and economy combined.

Twenty-First Century's Challenges for Primary Healthcare

Demographic and Epidemiological

In the twenty-first century, the world has faced unprecedented demographic and epidemiological challenges. The world population is aging, and it is facing new and emerging diseases, transiting from communicable diseases to NCDs. Maternal, newborn, child, adolescent and reproductive health have still remained an unfinished agenda. Globally, mortality rates have decreased across all age groups over the past five decades, with the largest improvements observed among children younger than 5 years. In $2005,19 \%$ of all deaths were among children, and $53 \%$ were among people aged 60 years 
and older (De Maeseneer et al., 2008). The World Health Organization (WHO) estimated in 2016, NCDs were responsible for 41 million of the world's 57 million deaths (71\%). A total of 15 million of these deaths were premature (30-70 years) (WHO, 2020). A similar trend has occurred in Africa despite the HIV/AIDS pandemic and poor socio-economic circumstances. Encouragingly, the number of deaths from HIV/AIDS fell from 3.9 million in 2001 to 1.1 million in 2018 (UNAIDS, 2020). There are wide differences in healthy life expectancy across the world. Global life expectancy at birth in 2016 was 72 years ( 74.2 years for females and 69.8 years for males), ranging from 61.2 years in the WHO African Region to 77.5 years in the WHO European Region (WHO, 2020). In almost all parts of the world, women live longer than men. Despite this demographic transition, the health system needs of women in less developed settings remain largely confined to reproductive matters, particularly maternal health and access to contraception. Significant progress has been made in reducing the disease burden due to tuberculosis (TB) and malaria, but because of disruptions of delivery of services due to COVID-19, the world might see a rise. More worrying indicators point to the fact that many countries in South Asia, Southeast Asia and sub-Saharan Africa have lagged behind in achieving at least some of the Millennium Development Goals (The International Bank for Reconstruction and Development \& The World Bank, 2006) (MDGs), while many countries will struggle in achieving SDGs, particularly Universal Health Coverage Goals.

\section{Scientific and Technological}

Scientific and technological innovations bring the prospects of new prevention, care, reorganisation of services and the overall system management possibilities. New evidence and scientific knowledge about diseases are likely to have an enormous influence on healthcare, especially in terms of diagnosis, management and prognosis. Since the early years of the twenty-first century, we have witnessed remarkable technological progress with the rapid development of less costly diagnostics and treatment, and fast and portable computing devices. Simultaneously, broadband and satellite technologies have helped in global connectivity with an increasing number of 'connected users' for information sharing (GSMA, 2019; ITU Statistic, 2020). Today, globally, millions of people even in the most remote areas of Africa and Asia have access to mobile and web-based information and communication technology. This has created opportunities for the point-of-care decision-making, better continuity of care and more effective communication between people, organisations and sectors. Availability of simple, low-tech and less costly, but most accurate, point of care, and nearpatient testing facilities have made it possible for timely and cost-effective diagnosis and care. New drug treatments have emerged, changing the old approach of expensive hospital-based disease management. Healthcare delivery has become more consistent, effective and cost-effective because of widespread evidence-based algorithmic disease management protocols. But while these developments offer many opportunities for improving health outcomes, the question politicians and public health leaders need to address is what innovative approaches need to be in place to translate these market-driven developments into needs-driven operation possibilities in developing countries, making universal healthcare a possibility.

Cultural and Ecological

Today, politicians play a major role in public health decision-making, balancing between economy and survival (Greenhalgh, 2004; Oliver, 2006).Today, patients act increasingly as 'consumers' (Navarro et al., 2006).This has consequences for the expectations and demands at the point of service delivery. Profit rather than health benefit has become more important, causing increasing medicalisation of daily life both in developed and developing countries, and the cost of medical 
services has soared beyond fiscal space. Due to the widening gap between the rich and poor, and a growing concentration of wealth among the fortunate few, there is a shift in the power of decisionmaking to the top of the income distribution. According to the National Health Account, in Namibia, $45 \%$ of the health budget was used by $18 \%$ of the wealthy population (Namibia Ministry of Health and Social Services, 2017). Today, behavioural, metabolic and environmental factors play a major role in shaping the disease burden. Ecological (food safety, climate change, water, sanitation and air pollution), socio-economic and individual lifestyle risks are a major concern, today. Poverty and unemployment have made access to healthcare services difficult and far more catastrophic health expenditures, worsening poverty (Agregbeshola \& Khan, 2018). People living in urban areas, particularly, the slum population, are living without healthcare and social support to cope with diseases.

\section{Globalisation}

Globalisation and change in economic policy has enabled low- and middle-income countries, participate in the global economy; when comparing the period from 1960 to 1980 with the rapidly globalising period from 1980 to 2000, growth in per capita gross domestic product (GDP) has not increased rapidly; rather, it has slowed down (Gurgul \& Lach, 2014). COVID-19 will further deteriorate economic growth consequently slowing the progress in both health and educational outcomes (Cornea, 2001; Weisbrot et al., 2004). For decades, Zambian health budget depended on foreign assistance, and about $60 \%$ was provided through foreign development assistance (PwC, 2019). Internal and external migrations due to conflicts, war and natural disasters have increased, causing difficulties in providing health services to these populations by national authorities and host countries. SARS, MERS and now COVID-19 have once again shown that the globalised world needs a coordinated global action and 'preparedness', focusing on the prevention and/or the rapid and appropriate response to disease outbreaks and disasters.

Twenty-first-century Primary Healthcare Needs to be Innovative

In order for healthcare systems to remain relevant, effective and responsive to changing population health needs, the health system needs to be innovative and flexible and needs to adapt and modify behaviour, practices, priorities and policies to reflect new knowledge and insights. Countries must have processes, organisations and a culture for change in place in order to make innovation possible. A vision for primary healthcare in the twenty-first century towards achieving universal health coverage and the Sustainable Development Goals (SDGs) provides the rationale for and foundation to release the potential of primary healthcare, with its continued political and economic focus on the right to integrated, quality, personal and population-level primary care. We need to take into account that health, as a multi-sectoral social and economic construct, which is dependent on many sectors and on community engagement and empowerment with respect to health services, is a must (OECD, 2020). The Robert Wood Foundation in 1996 stated 'Health care today is characterized by more to know, more to manage, more to watch, more to do, and more people involved in doing it than at any time in the nation's history. Our current methods of organizing and delivering care are unable to meet the expectations of patients and their families because the science and technologies involved in health care - the knowledge, skills, care interventions, devices, and drugs - have advanced more rapidly than our ability to deliver them safely, effectively, and efficiently' (The Robert Wood Johnson Foundation, 1996). Primary healthcare innovation must ensure all citizens have lifelong, affordable access to quality healthcare. In realising the primary healthcare potential, a truly transformational, innovative and creative approach through making necessary changes by adjusting policies for a patient-oriented, need-based and provider-friendly healthcare system would be needed. Transformation, innovation and creativity need to address: (a) improving allocative, 
technical and service delivery efficiencies; (b) improve the effectiveness and responsiveness of care; (c) improving access and equity of care; (d) improve monitoring and accountability (Bourgueil et al., 2012; Buerhaus, 2018; Mousquès, 2011; Ranjan et al., 2015; Schäfer et al., 2016; Shipman \& Sinsky, 2013). Innovation can be defined as 'the design, invention, development, and/or implementation of new or altered products, services, processes, systems, organizational structures, or business models for the purpose of creating new value for customers along with financial feasibility'. More comprehensively, innovation represents the implementation of new or significantly improved products, services or processes. It can also imply new organisational models, methods of service delivery, ways of relating to customers and approaches to marketing (Deloitte, 2014; Fairall et al., 2015; Haughom, 2014). Driven by the compelling needs of an increasing number of people seeking healthcare services and the ever-increasing cost of providing healthcare services, a number of developing and developed countries have emerged as nerve centres for responsive, quality and economical healthcare innovations. The drivers of innovations are many in the emerging markets. In order to face the unique and sensitive developmental challenges and to drive innovation, these countries adopted need-based indigenous solutions and perspectives.

There may be three possible responses to address the health challenges of the twenty-first century: increasing health funding (increasing inputs), rationing health services (restricting outputs) or increasing productivity through innovation (doing things differently and more efficiently with what one has) (More, 2019).Fiscal constraints (austerity programmes), competing demands, and increased population awareness and expectations, neither more funding nor restriction of services may be a popular or first choice for politicians. Therefore, countries need to be innovative in providing quality healthcare services with what they have. Significant and sustained productivity gains can be made through management models and innovations that change how services are delivered. It is observed that while innovative activity might be relatively easy to define, it is notoriously difficult to measure. However, measuring diffusion of innovative measures in the state sector is often relatively straightforward (compared to the private sector), given the greater ability to directly observe activities or outputs (Nolan, 2018). In many countries, globally, innovation in healthcare has been characterised in short term as the 'introduction of a new concept, idea, service, process, or product aimed at improving access to availability and affordability of (government and people) treatment, diagnosis, education, outreach, prevention, and research. The long-term goals of these innovations are aimed at improving quality, safety, outcomes, efficiency, and costs' (Omachonu \& Einspruch, 2010). This has involved looking at whether the authorising environment is conducive to innovation, what innovations (particularly new service models) have emerged, whether and how new service models have diffused across the sector and what impact they may have had on improving outcomes, quality, efficiency and costs.

\section{Some Innovative Primary Healthcare Approaches}

New Zealand

In order to meet high demand, provide significant and sustained care services, New Zealand introduced a process of innovation to change how services are delivered. A not-for-profit 'Primary Health Care Organization (PHO)' was set up as the local delivery structure under the Primary Health Care Strategy in New Zealand (More, 2019). The Primary Health Care Strategy has encouraged the development of several different models of care and a range of service innovations such as online and telephone services, integrated or team-based work, new and expanded health workforce roles, coaching and self-management, group consultations and changes to business organisation and processes (Pullon et al., 2009). This process required the organisation to provide a set of essential primary healthcare services to an enrolled population. This was funded by the government through 
district health boards (DHBs). This entailed a shift in government funding from fee-for-service payments (per patient per consultation) to capitation funding (a flat rate per head of enrolled population, weighted by age and gender). Each patient still needed to pay co-payments (the fee that patients pay each time they use a medical service), but to cap increase in payment, co-payment was decided by the boards. Three different models were adopted by different districts: (a) a low fee (with higher capitation), walk-in visits and accessible hours Nevada Health service delivery model. Nevada health and its subsidiaries are corporate pro-profit businesses; (b) do 'whatever it takes' acute demand funded by the board to reduce visit to the emergency department or admission to hospital. This model was supported with a comprehensive IT support; (c) transforming Health Care Homes by a multidisciplinary team-based model/practice to better manage the mix of acute, routine and preventive treatments by changing the input mix (e.g., staff time, practitioner tools and business activities) to ensure the right mix of staff to focus more on proactive and preventive care and on patients with more complex needs. The Health Care Home model was adopted by Pinnacle Midlands Health Network PHO, from a model used by Group Health in the USA. It first began operating in three practices in Hamilton in 2011, and it is now being implemented in more than 128 general practices across New Zealand. Although that seems like a fairly rapid rate of expansion, the first 3-4 years saw the establishment of relatively few new Health Care Home $(\mathrm{HCH})$ practices, and most of this expansion has occurred after the New Zealand Health Care Home Collaborative was established in 2016. Since then, the expansion of the model has been quite rapid.

\section{Bangladesh}

Bangladesh has an estimated population of 165 million people. Although the urban population has rapidly grown, reaching around $36.6 \%$ in 2018 , the rural population still remains the largest population group in the country. Currently, one-third of the urban population is thought to live in slum settlements and comprise the bulk of the lowest two wealth quintiles. Bangladesh's government is thus faced with the challenges of providing healthcare services to the vast rural and growing urban populations. In Bangladesh, the Ministry of Health and Family Welfare (MoH\&FW, or $\mathrm{MoH}$ ) is responsible for health policy formulation, regulation and administration, as well as the provision of secondary and tertiary healthcare at the national level and primary healthcare (PHC) in rural areas. However, preventive and PHC provision in urban areas is the responsibility of municipalities and City Corporations (CC), referred to as local government institutions (LGIs), which fall under the Ministry of Local Government, Rural Development and Cooperatives (MoLGRD\&Co, or MoLG). The lack of capacity of local government to provide healthcare to increasing urban population, particularly those living in slums effectively has become apparent. The vast rural population demand for health also could not be met with subdistrict and union-level healthcare facilities. Therefore, Bangladesh needed different innovative approaches. Urban Primary Healthcare: In 1998, the MoLG, with the assistance of the Asian Development Bank (ADB) and other donors, launched the Urban Primary Healthcare Project to contract out to nongovernmental organisations (NGOs) the provision of free PHC services for the urban poor (Islam et al., 2018). The project is managed by a Project Management Unit (PMU) within the Ministry, which provides technical, administrative and logistical leadership for project implementation. Over the three phases, project coverage expanded from four large urban centres with a total catchment population of about nine million to 13 urban centres, including smaller municipalities and a 10 million catchment population with a free comprehensive healthcare package today. Community Clinic: Bangladesh has established more than 13,000 community clinics (CCs) to provide primary healthcare with a plan of each covering a population of around 6,000 and within less than 30-min walking distance throughout the country (Riaz et al., 2020). People of the catchment area provided the land and participate in the management process. This public and community partnership provided opportunities in healthcare 
delivery and helped in offering healthcare services right at the doorstep of people living in rural areas. The availability of basic healthcare services at their doorstep and referrals of complicated cases to the higher-level facilities have been possible due to the establishment of these grassrootslevel health facilities.

India

India with its 1.4 billion population and the majority living in rural areas with increasing urbanisation (34\% in 2017) faces a double burden of infectious and increasing NCDs plus unfinished agenda ofburden of maternal, newborn and child health. Poor sections of the population in rural and urban areas, particularly, the slum populations, suffer the most because of their lack of ability to access healthcare (Lait et al., 2017). However, in India, healthcare provision and delivery are the responsibility of states (India has 28 states and 8 union territories). In 2016, the publication of India's burden of disease, low health access and quality (HAQ) index and more than 60 million Indians pushed into poverty because of catastrophic out-of-pocket medical expenses have justified urgent action towards universal healthcare access, particularly by its vast poor sections of the population. The prime minister of India initiated and started a bold initiative called Ayushman Bharat Yojana, with a plan to provide free care to 100 million poor households or 500 million people identified according to the Socio-Economic and Caste Census 2011 (Pareek, 2018; The Economic Times, 2019 ; Zodpey \& Farooqui, 2018). The initiative includes without any prejudgement of family size, age or gender, or previous medical conditions, free healthcare services at public or private facilities, including hospital specialised care when needed. In February 2018, when the programme was initiated, 20 states committed to join. In September 2018, shortly after launch, five states and territories declined to participate in the programme: Delhi, Telagana, Odisha, Kerala and Punjab (Moneycontrol News, 2018). This initiative has provided opportunities for 500 million poor people to avail timely free quality care in public as well as private healthcare facilities. In addition to the insurance, more importantly, the government under Ayushman Bharat scheme, has embarked on a mission to open 150,000 'health and wellness centres', which provide screening for NCDs, such as hypertension, diabetes and selected cancers, and preventive and treatment services covering both communicable and chronic noncommunicable diseases close to where the people live. Thus, this unique initiative provides an unprecedented opportunity to ensure primary healthcare and achieve the universal health coverage.

Thailand

In contrast to the Western model of family practice (which remains largely focused on point-ofcontact care), in most areas in Thailand, health needs and limited resources amplified the importance of and the need for action at the community level. Physicians needed to be able to move outside the hospital setting, conceptually, and literally, in order to have an impact on the health problems of the communities they serve (Williams, 2002). In Thailand, until the 1990s, primary healthcare consisted of health centres that started out as 'antennas' of hospitals (Pongsupap, 2007). The focus of care was on technical adequacy and clinical decisions, not on patient-centredness and quality of human relations. This did not help Thailand in achieving universal health coverage, and therefore, Thailand adopted the policy of explicitly linking and strengthening first-line health service and family medicine development. The Ministry of Public Health viewed the family practice as having the potential to transform healthcare delivery in Thailand in order to bring a new style of relating to patients, along with a renewed understanding of the process of health and illness, and a new emphasis on illness prevention and coordination of care. Thailand introduced family medicine as a new specialty in 1998, and it was gradually recognised as a medical speciality in its own right. The first health centre to feature the family practice model was established in 1991 . They hope the 
family practice will lead to improved access to care, increase emphasis on prevention at the community level and reduce the cost of care. Due to the increased focus on family medicine development under the new Thai Universal Coverage policy, primary care units were strengthened, shifting the centre from specialist-in-hospital to family practitioner-in-community. The emphasis on primary care in the Universal Coverage scheme represents a bold departure from the traditional, hospital-dominated Thai healthcare system. Nurses and health workers serve as the backbone of service delivery at the primary care level (Towse, 2004).

\section{South Africa}

Primary healthcare originated in South Africa in the 1930s with the development of communityorientated primary healthcare albeit later smothered under apartheid. Family medicine has since been limited to private practice (Moosa, 2006). The National Health Services, since the 1990s, has struggled to transform apartheid hospital-centric care towards primary healthcare. Previously, primary healthcare was mainly organised to nurse-based clinics (with periodic doctor visits) in the framework of the health districts with a strong community and programmatic orientation in the District Health Services. However, as few doctors visited the clinics, patients started bypassing clinics to get to doctor-based hospitals. Patients also complained of deteriorating quality of care. In addition, the increasing verticatisation of disease-orientated programmes has endangered primary healthcare services delivery. Addressing the above-mentioned challenges, the government took the initiative to transform family medicine as a specialist discipline since 2007 and has progressively embraced the challenges of a new South Africa. There has been a growing partnership between universities and provincial Departments of Health since the 2000s. Family physicians are based across district hospitals, community health centres, clinics and communities in order to improve the quality of clinical care in an integrated model of care. Family physicians offer clinical supervision, referral support and links to district hospitals. District Health Services and family medicine principles have grown in alignment. Trained family nurse practitioners and the clinical associate (mid-level worker) are also a part of this mix in the light of doctor shortages, and this is being supported by family physicians in South Africa as a procedural assistant in district hospitals (Anstey et al., 2018; Horrocks, 2002). The private health sector (consuming more than $60 \%$ of health expenditures and serving less than $10 \%$ of the population mostly with specialist hospital care) has embraced primary healthcare to manage costs and the ability to balance costs, quality and access to healthcare with clinical teamwork.

\section{Ghana}

Digital technologies like mobile phones have provided solutions for improving access to healthcare information and services in low- and middle-income countries. The capabilities of digital communication technologies to create, store, retrieve and transmit information among mobile users, including healthcare managers, may improve and support the delivery of healthcare solutions (Anstey et al., 2018). Given that significant levels of maternal and child mortality in the Upper East region of Ghana and also that the healthcare needs of these groups are different and time-sensitive, improved timely information for health workers and clients in these groups holds the most potential for increasing positive health outcomes. Taking the advantage of mobile connectivity and its wide use in Ghana in general, and the region in particular, the Mobile Technology for Community Health (MoTeCH) Initiative has introduced mobile technology in primary healthcare services delivery to focus on the needs of individuals who are most associated with the major burden of disease in this setting (Bhavnani et al., 2016; MacLeod et al., 2012). The initiative aimed at providing timely information of (a) pregnant women or young mothers, (b) women during times of delivery; a majority of whom are delivering at home, (c) neonates, particularly those requiring outreach in the 
first $48 \mathrm{~h}$ of life and (d) children less than 1 year of age who require immunisation and curative health services. The MoTeCH mobile phone data collection system is based on open XData (www.openxdata.org) with a relatively small memory footprint on the mobile phone. Nurses are given a low-cost mobile phone (less than US\$50) to enter data and receive MoTeCH systemgenerated messages about patients who are overdue for seeking routine healthcare. The data entered by the nurse are also used to automate the generation of reports for the district and regional health administrators and planners. Women have said that $\mathrm{MoTeCH}$ alerts inform them that they were approaching their expected delivery date and allowed them to be more prepared when they began labour. Client interviews have also found that MoTeCH informational messagespromoting facility-based delivery and getting to a health facility as soon as possible after the onset of labour-have influenced their delivery preferences and experiences. However, challenges associated with the lack of electricity for charging mobile and willingness of neighbours in using their mobile need to be addressed for scaling up. Other African and Asian countries have also increased the usage of mHealth technology (Ojo, 2018).

\section{Belgium}

Addressing the challenges of the hospital-centric systems, the government in Belgium, during the past 30 years, has developed an initiative to provide care services by any provider or facility for the patient, operating in a fee-for-service system with a $30 \%$ cost-share by the patient. Today, there is a favourable environment for shifting emphasis from hospital-centric care to the development of primary healthcare. The changes in the delivery system have been introduced and maintained through continuous negotiations, where insurers and professional organisations compromise over the development of the fee-for-service system. In Belgium, initiatives by motivated health professionals and by civil society have begun the development of interdisciplinary ;community health centres', with a focus on equity and community participation. The health centres negotiated the creation of a capitation system, without financial disincentive, for registered patients. This optimised access to care, especially for socially vulnerable groups. With increasing attention to equity in healthcare, mechanisms were established by the government to enhance insurance (with almost $100 \%$ coverage) and to stimulate access and quality. Accessible care was developed for unregistered people who have migrated to Belgium, offering them access for 'urgent medical care'. But in practice, this concept was interpreted as 'all the care needed'. Apart from personal care, orientated towards individuals and groups, community-orientated primary care actions were developed. Examples are actions to address the poor physical health of youth through the creations of playgrounds and organisation of activities and actions to improve access to dental care (Art, 2007). Currently, the focus is on strengthening home care, development of disease management and implementation of guidelines with a focus on quality improvement. The federal government is responsible for the payment mechanisms of healthcare providers and hospitals, whereas the regional government holds responsibility for prevention, organisation of home care and nursing homes, and ambulatory mental healthcare. Due to different political orientations, decisions made at the federal and local regional levels have become a bottleneck in the smooth running of the system. Lack of a coordinated country-wide plan has made the same institution dependent on different authorities, hindering the development of a comprehensive care model.

\section{Canada}

Canada has 13 provincial and territorial healthcare systems that operate within a national legislative framework, the Canada Health Act (1984) (Hutchison et al., 2011). Most of the healthcare in Canada is publicly financed but privately delivered. Family physicians comprise $51 \%$ of the physician workforce. Overall, $91 \%$ of Canadians say they have a regular source of care, usually a family 
physician. During the 1980s and 1990s, primary healthcare reform in Canada was characterised by false starts, myriad small-scale pilot and demonstration projects, futile advocacy of fundamental system-wide change and failure to embrace the alternative strategy of progressive incremental change (Hutchison et al., 2001). The need for primary healthcare reform agenda became stronger by the findings and recommendations of two national reviews of healthcare, the growing political and public concern about healthcare access and quality, the mounting dissatisfaction among family physicians with their working conditions and their ability to provide high-quality care, and medical school graduates' declining interest in family medicine. These concerns were both fuelled and reflected by the media, with particular attention to emergency room 'overcrowding', which was increasingly attributed to patients having difficulty accessing family physicians. In this climate, politicians along with organised medical service entities in several provinces-having previously adopted a cautious, if not hostile, attitude towards primary healthcare reform - began to negotiate the nature and terms of that reform in the early 2000s. In 2000, in keeping with the recommendations of various federal and provincial reports, the government (the prime minister of Canada and the provincial and territorial premiers) established Primary Health Care Transition Fund to accelerate primary healthcare reform. The 2003 First Ministers Health Accord included a US\$16 billion federal investment in the Health Reform Fund, which was targeted to primary healthcare, home care and catastrophic drug coverage. In 2004, Canada agreed to establish a goal of $50 \%$ of Canadians having $24 / 7$ access to multidisciplinary primary healthcare teams by 2011 . The goal and objectives included interprofessional primary healthcare teams, group practices and networks, patient enrolment with a primary care provider, financial incentives and blended-payment schemes, primary healthcare governance, expansion of the primary healthcare provider pool, implementation of electronic medical records, and quality improvement training and support. These objectives of Canadian primary healthcare reform mirror the Institute of Medicine's six goals for improvement: safety, effectiveness, efficiency, person-centredness, timelines and equity, with a heavy emphasis on timelines and effectiveness and on cost control rather than efficiency. Patients' formal enrolment with a primary care physician or group is an integral feature of primary care reform instituted only in Quebec and Ontario (Bozzini, 1988). In both cases, enrolment is voluntary. More than half of the Quebec population is currently registered with a family physician; enrolments with a primary care physician in Ontario grew from 600,000 in 2002 to 9.5 million in February $2011-72 \%$ of the provincial population.

\section{A Way Forward}

Countries, in order to provide healthcare and achieve universal coverage, must assess the current system of healthcare deliveries and decide on future actions. The starting point would be not more funding, and doing the same thing again and again getting the same results, but adopting a culture of change and reorganisation of services, being more efficient and improve quality and be accountable with what we have. Going forward, the emphasis on innovation promises to accelerate rapidly and produce exponential change in important areas, including prevention, more personalised care tailored specifically to a patient's needs, more efficient and proactive technology-enabled care models, more integrated and comprehensive delivery organisational designs, and additional creative technology-enabled options for effective health encounters (e.g., patient to provider, provider to provider and patient to patient). Countries have shown that innovation is possible and the time for bringing change is now.

Declaration of Conflicting Interests

The author declared no potential conflicts of interest with respect to the research, authorship and/or publication of this article. 
Funding

The author received no financial support for the research, authorship and/or publication of this article.

\section{References}

Agregbeshola, B. S., \& Khan, S. M. (2018). Out-of-pocket payments, catastrophic health expenditure and poverty among households in Nigeria 2010. Int J Health Policy Manag, 7(9), 798-806.

https://doi.org/10.15171/ijhpm.2018.1 Anstey, T. A., Goudgeb, J., Gomez-Olivec, F. X., \& Griffithsa, F. (2018). Mobile phone use among patients and health workers to enhance primary healthcare: $A$ qualitative study in rural South Africa. Social Science \& Medicine, 198, 139-147. Art, B. (2007). Towards unity for health utilising community-oriented primary care in education and practice. Education for Health, 20(2), 74. Bhavnani, S. P., Narula, J., \& Sengupta, P. P. (2016). Mobile technology and the digitization of healthcare. European Heart Journal, 37(18), 1428-1438. https://doi.org/10.1093/eurheartj/ehv770 Bourgueil, Y., Jusot, F., \& Henri, L. (2012). In what way can primary care contribute to reducing health inequalities? A Review of Research Literature. Question d'Economie de la Santé. http://www.irdes.fr/EspaceAnglais/ Publications/IrdesPublications/QES179.pdf Bozzini, L. (1988). Local Community Services Centers (CLSCs) in Québec: Description, evaluation, perspectives. Journal of Public Health Policy, 9(3), 346375. Buerhaus, P. (2018). Nurse practitioners: A solution to America's primary care crisis. American Enterprise Institute. Cornea, G. A. (2001). Globalization and health: Results and options. Bulletin of the World Health Organization, 79(9), 834-841. Deloitte. (2014, August). Innovative and sustainable health care management: Strategies for growth. Conference background note.

https://www2.deloitte.com/content/dam/Deloitte/in/Documents/life-sciences-health-care/inlshcinnovative-healthcare-noexp.pdf Fairall, L., Bateman, E., Cornick, R., et al. (2015). Innovating to improve primary care in less developed countries: Towards a global model. BMJ Innovations, 1, 196203. GBD 2015 Risk Factors Collaborators. (2016). Global, regional, and national comparative risk assessment of 79 behavioural, environmental and occupational, and metabolic risks or clusters of risks, 1990-2015: A systematic analysis for the Global Burden of Disease Study 2015. The Lancet, 388(10053), 1659-1724. Greenhalgh, T. (2004). 'Health for me': A sociocultural analysis of healthism in the middle classes. Br Med Bull, 69, 197-213. GSMA. (2019, July). The state of mobile internet connectivity 2019. https://www.gsma.com/mobilefordevelopment/ wp-

content/uploads/2019/07/GSMA-State-of-Mobile-Internet-Connectivity-Report-2019.pdf Gurgul, H., \& Lach, L. (2014). Globalization and economic growth: Evidence from two decades of transition in CEE. Economic Modelling, 36, 99-107. https://doi.org/10.1016/j.econmod.2013.09.022 Haughom, J. (2014, December). Innovation in health care: Why its needed and where its going. Health Catalyst. https://www.healthcatalyst.com/innovation-in-healthcare-why-needed-where-going Horrocks, S. (2002). Systematic review of whether nurse practitioners working in primary care can provide equivalent care to doctors. British Medical Journal, 324, 819-823. Huntley, A., Lasserson, D., Wye, L., Morris, R., Checkland, K., England, H., Salisbury, C., \& Purdy, S. (2014). Which features of primary care affect unscheduled secondary care use? A systematic review. BMJ Open. http:// dx.doi.org/10.1136/bmjopen-2013-004746. Hutchison, B., Abelson, J., \& Lavis, J. (2001). Primary care in Canada: So much innovation, so little change. Health Affairs, 20(3), 116-131.

https://doi.org/10.1377/hlthaff.20.3.116 Hutchison, B., Levesque, J.-F., Strumpf, E., \& Coyle, N. (2011). Primary Health Care in Canada: Systems in motion. Milbank Quarterly, 89(2), 256-288. https://doi.org/10.1111/j.1468-0009.2011.00628.x

Islam, R., Hossain, S., Bashar, F., Khan, S. M., Sikder, A. A. S., Yusuf, S. S., \& Adams, A. M. (2018). Contractingout urban primary health care in Bangladesh: a qualitative exploration of 
implementation processes and experience. International Journal for Equity in Health, 17, 93. https://doi.org/10.1186/s12939-018-0805-1 ITU Statistic. (2020). Global and regional ICT data. ITU. De Maeseneer, J., Moosa, S., Pongsupap, Y., \& Kaufman, A. (2008). Primary health care in a changing world. British Journal of General Practice, 58(556), 806-809.

https://doi.org/10.3399/bjgp08X342697 Kirkland, S., Soleimani, A., \& Newton, A. (2018). The impact of pediatric mental health care provided outpatient, primary care, community and school settings on emergency department use-A systematic review. Child and Adolescent Mental Health, 23, 4-13. Lait, D., Dandona, R., Kumar, G. A., Shukla, D. K., Paul, V. K., Balakrishnan, K., Prabhakaran, D., Tandon, N., Salvi, S., Dash, A. P., Nandakumar, A., Patel, V., Agarwal, S. K., Gupta, P. C., Dhaliwal, R. S., Mathur, P., Laxmaiah, A., Dhillon, P. K., Dey, S., ..., Swaminathan, S. (2017). Nations within a nation: Variations in epidemiological transition across the states of India, 1990-2016 in the global burden of disease study. The Lancet, 390(10111), 2437-2460. https://doi.org/10.1016/S01406736(17)32804-0 Macinko, J., Starfield, B., \& Erinosho, T. (2009). The impact of primary healthcare on population health in low- and middle-income countries. Journal of Ambulatory Care Management, 32(2), 150-171. http://dx.doi.org/10.1097/ jac.0b013e3181994221 MacLeod, B., Phillips, J., Stone, A. E., Walji, A., \& Awoonor-Williams, J. K. (2012). The architecture of a software system for supporting community-based primary health care with mobile technology: The mobile technology for community health (MoTeCH) initiative in Ghana. Online Journal of Public Health Informatics, 4(1). https:// doi.org10.5210/ojphi.v4i1.3910 Moneycontrol News. (2018, September 24). 5 states opted out of Ayushman Bharat: Here's why. Moneycontrol.

https://www.moneycontrol.com/news/india/5-states-opted-out-of-ayushman-bharat-heres-why2979691.html Moosa, S. A. H. (2006). Community-oriented primary care (COPC) in district health services of Gauteng, South Africa. South African Family Practice, 48(4), 6-11. More, S. (2019). Innovation in primary healthcare can it improve health sector productivity and health outcomes. Policy Quarterly, 15(1), 68-72. Mousquès, J. (2011). The regrouping of primary health care professionals: Economic perspective in terms of performance. Namibia Ministry of Health and Social Services. (2017, September). Namibia 2014/15 Health Accounts Report. Namibia Ministry of Health and Social Services. Narin, J. P. (2020, September 25). Proactive approach shapes HP's Covid battle. Comment. The Tribune. https:// www.tribuneindia.com/news/comment/proactive-approachshapes-hps-covid-battle-136103 Navarro, V., Muntaner, C., Borrell, C., et al. (2006). Politics and health outcomes. The Lancet, 368, 1033-1037. Nolan, P. (2018). Measuring productivity in the health sector. Policy Quarterly, 14(3), 40-45. OECD. (2020). Realising the potential of primary health care, OECD Health Policy Studies. OECD Publishing. https://doi.org/10.1787/a92adee4-en Ojo, A. (2018). mHealth interventions in South Africa: A review. SAGE Open, 1-8. https://doi. org/10.1177/2158244018767223 (https://journals.sagepub.com/home/sgo). Oliver, T. R. (2006). The politics of public health policy. Annual Review of Public Health, 27, 195-233. https://doi. org/10.1146/annurev.publhealth.25.101802.123126 Omachonu, V., \& Einspruch, N. (2010). Innovation in health care delivery systems: A conceptual framework. Innovation Journal, 15(1). Pareek, M. (2018, July 31). Ayushman Bharat-National Health Protection mission a way towards universal health cover by reaching the bottom of the pyramid to be a game changer or non-starter. International Journal of Advanced and Innovative Research, 7(7). https://doi.org/10.5281/zenodo.1341912 Pongsupap, Y. (2007). Introducing a human dimension to Thai health care: The case for family practice (PhD thesis). VUBPRESS. Primary Care Development Corporation. (2020, June). To address COVID-19 disparities, PCDC urges New York sate to invest in primary care. https://www.pcdc.org/covid-19-disparities-new-yorktestimony/?creative $=440829519542 \&$ keyword $=$ covid19\%20disparities\&matchtype $=p \&$ network $=g \&$ device $=c \& g c l i d=E A l a I Q o b C h M I 80 H M k \_y D 7 A I V T-$ btCh3J5AUYEAAYAiAAEgLIfPD_BwE Public Health England. (2020, August). Disparities in the risk and 
outcomes of COVID-19. https://assets.publishing. service.gov.uk/government/uploads/ system/uploads/attachment_data/file/908434/Disparities_in_the_risk_

and_outcomes_of_COVID_August_2020_update.pdf Pullon, S., McKinlay, E., \& Dew, K. (2009). Primary health care in New Zealand: The impact of organisational factors on teamwork. British Journal of General Practice, 59(560), 191-197. https://doi.org/10.3399/bjgp09X395003 PwC. (2019, September). Walking a tightrope: National budget 2020. https://www.pwc.com/zm/en/assets/pdf/ zambia-budget-bulletin-2020.pdf Ranjan, P., Kumari, A., \& Chakrawarty, A. (2015). How can doctors improve their communication skills? Journal of Clinical and Diagnostic Research, 9(3), JE01-4. Riaz, B. K., Ali, L., Ahmad, S. K., Islam, M. Z., Ahmed, K. R., \& Hossain, S. (2020). Community clinics in Bangladesh: A unique example of public-private partnership. Heliyon, 6, e039508.

https://doi.org10.1016/j. heliyon.2020.e03950 Rimmer, A. (2020). Covid-19: Disproportionate impact on ethnic minority healthcare workers will be explored by government. British Medical Journal. https//doi.org/10.1136/bmj.m1562 Rosano, A., Loha, C. A., Falvo, R., van der Zee, J., Ricciardi, W., Guasticchi, G., \& Giulio de Belvis, A. (2013). The relationship between avoidable hospitalization and accessibility to primary care: A systematic review. European journal of public health, 23(3), 356-360. http://dx.doi.org/10.1093/eurpub/cks053 Schäfer, W., Boerma, W. G. W., Spreeuwenberg, P., Schellevis, F. G., Groenewegena, P. P. (2016). Two decades of change in European general practice service profiles: Conditions associated with the developments in 28 countries between 1993 and 2012. Scandinavian Journal of Primary Health Care, 34(1), 97-110. Shipman, S., \& Sinsky, C. (2013). Expanding primary care capacity by reducing waste and improving the efficiency of care. Health Affairs.

https://www.healthaffairs.org/doi/full/10.1377/hlthaff.2013.0539 The Economic Times. (2019, March 6). Ayushman Bharat on way to become world's largest free healthcare scheme: Arun Jaitley. The Economic Times. https://economictimes.indiatimes.com/industry/healthcare/biotech/ healthcare/ayushman-bharat-on-way-to-become-worlds-largest-free-healthcare-scheme-arunjaitley/articleshow/68288261.cms?from=mdr The Guardian Weekly. (2020, August 7). How we live now. The Guardian Weekly, 203(5), 11. The International Bank for Reconstruction and Development, \& The World Bank. (2006). Global Monitoring report 2006: Millennium Development Goals: strengthening mutual accountability, aid trade and governance. IBRD. The Robert Wood Johnson Foundation. (1996). Chronic care in America: A 21st century challenge. The Robert Wood Johnson Foundation. http://www.rwjf.org/library/chrcare/ Towse, A. (2004). Learning form Thailand's health reforms. British Medical Journal, 328(7431), 103-105. Trivedy, C., Mills, I., \& Dhanoya, O. (2020). The impact of the risk of COVID-19 on Black, Asian and Minority Ethnic (BAME) members of the UK dental profession. British Dental Journal, 228(12), 919-921. UNAIDS. (2020). Global HIV\&AIDS statistics-2020 fact sheet. UNAIDS. van Loenen, T., van den Berg, M. J., Westert, G. P., \& Faber, M. J. (2014). Organizational aspects of primary care related to avoidable hospitalization: a systematic review. Family Practice, 31(5), 502-516. http://dx.doi. org/10.1093/fampra/cmu053 Weisbrot, M., Baker, D., Kraev, E., \& Chen, J. (2004). The scorecard on globalization 1980-2000: Its consequences for economic and social well-being. In V. Navarro, \& C. Muntaner (Eds.), Political and economic determinants of population health and well-being: Controversies on developments (pp. 91-114). Baywood Publishing Company. Williams, R. L. (2002). Family practice in Thailand: Will it work? Journal of the American Board of Family Practice, 15(1), 73-76. Wolters, R., Braspenning, J., \& Wensing, M. (2017). Impact of primary care on hospital admission rates for diabetes patients: A systematic review. Elsevier Ireland Ltd. http://dx.doi.org/10.1016/j.diabres.2017.05.001 World Health Organization (WHO). (2020). Global Health Statistics 2020. WHO. Zodpey, S., \& Farooqui, H. H. (2018, April). Universal health coverage in India: Progress achieved \& the way forward. The Indian Journal of Medical Research, 147(4), 327-329. https://doi.org/10.4103/ijmr.IJMR_616_18 